\title{
Magnesium oxide as an additive with polymeric sulfur cathode and modified glass fiber separator for high performance lithium-sulfur batteries
}

\author{
Maryam Sadat Kiai* \\ Nano-Science and Nano-Engineering Program, Graduate School of Science, Engineering and \\ Technology, Istanbul Technical University, Istanbul 34469, Turkey
}

Corresponding author. Dr. Maryam Sadat Kiai

* Email address: maryamskiai@gmail.com

\begin{abstract}
The lithium ion technology is now beginning to enter into electric vehicles and grid storage of renewable energies (solar and wind energy). However, the current lithium ion technology has reached the limitations of their charge-storage capacity and energy density. Therefore, alternative cathode and anode materials that offer higher capacities need to be developed. Lithium- sulfur battery with sulfur based cathode undergoes conversion reactions while accommodating more ions and electrons as promising options to overcome the charge-storage limitations of lithium ion battery. Cost, cycle life, safety, energy, power, and environmental impact should be considered for commercializing modified lithium-sulfur batteries. In this study highly conductive and lightweight cathode materials consist of poly 1,5-diaminoanthraquinone (PDAAQ) and magnesium oxide $(\mathrm{MgO})$ have been considered to increase cycle life and performance of lithium-sulfur batteries. Modified one and double side coated glass fiber separator also was investigated to improve confinement of active materials on the pores and prevented dissolution
\end{abstract}


of undesired materials in the electrolyte. The cells with $\mathrm{MgO} / \mathrm{PDAAQ} / \mathrm{S}$ cathode and uncoated glass fiber separator showed initial discharge capacity of $1000 \mathrm{mAh} \mathrm{g}^{-1}$ at $2 \mathrm{C}$. The discharge capacity decreased at $~ 900 \mathrm{mAh}^{-1}$ for 5C. MgO/PDAAQ/S cathode and double side coated glass fiber separator showed the higher capacities of $\sim 1250$ and 1170 at 2C and 5C respectively.

\section{Introduction}

Li-S battery are increasingly being investigated due to high theoretical and practical energy density. Sulfur as a cheap cathode with high abundancy and non-toxicity is the reason why Li ion batteries with heavy-metal based Li-ion cathodes should be replaced by Li-S system to satisfy environmentally and economically consideration. There are several limitations with Li-S technology which cause a gap between the theoretical and practical energy density of Li-S battery. The major problems are related to very complex reaction mechanism of Li-S and polysulfides formation and the second comes from lithium metal anode oxidation. Cyclic stability is also limited by some degradation which occur inside the cell e.g., deposition of intermediate products $\left(\mathrm{Li}_{2} \mathrm{~S}_{2}, \mathrm{Li}_{2} \mathrm{~S}\right)$ at the cathode surface and degradation of carbon based cathode skeleton as result of this decomposition. Also polysulfides could react with electrolyte and suppress ion mobility with undesired reactions in the electrolyte [1-4].

Nanostructured carbonous host materials are the most important additives of the sulfur cathode to enhance surface areas and increase porosity to hinder polysulfides diffusing into electrolyte. However, recently application of novel materials with chemical bonding with polysulfides are investigated and found introducing of functional groups into the carbon framework, such as $\mathrm{O}$,

$\mathrm{N}, \mathrm{B}, \mathrm{S}$ could enhance polysulfides adsorption by chemical binding as well as physical restriction. [5-9]. 
Application of oxygen containing group such as graphene oxide (GO) in the cathode is studied recently due to excellent chemical stability and ultra-high surface area as well as it is functionalized with hydroxyl and epoxide groups to increase polarity. Zhang et al. performed a chemical reaction-deposition method to produce GO sulfur sheets. These chemical interactions between sulfur and the functional groups on GO sheet surface were confirmed by Ab initio calculations. For this purpose X-ray absorption spectroscopy (XAS) measurements was performed, and the results exhibited that the GO-S composite contains a great amount of S-O and S-C bonds. Electrochemical results also revealed that the Li-S cells with GO-S composite cathode showed initial capacity of $1400 \mathrm{mAh} \mathrm{g-1}$ and capacity retained at $950 \mathrm{mAh} \mathrm{g}^{-1}$ after 100 cycles [10].

Hue et al. reported new mesoporous $\mathrm{TiO}_{2} /$ reduced graphene oxide $(\mathrm{rGO})$ as an efficient polysulfides trapping in the cathode. $\mathrm{TiO}_{2} @ \mathrm{rGO}$ hybrid structure has been shown to trap polysulfides products effectively by means of strong chemical bonding with oxygen double bonds. Also incorporation GO in the cathode enhanced the electrical conductivity and improved polysulfides trapping ability providing large surface area. They found that incorporation of $\mathrm{TiO}_{2} @ \mathrm{rGO}$ in the cathode exhibits capacities of 1116 and $831 \mathrm{mAh} \mathrm{g}^{-1}$ at the current densities of $0.2 \mathrm{C}$ and $1 \mathrm{C}\left(1 \mathrm{C}=1675 \mathrm{~mA} \mathrm{~g}^{-1}\right)$ after 100 and 200 cycles [11]. Application of metal oxides exhibited strong absorption with polysulfides by chemical bonding, and enhanced the utilization of active material [12].

Chen et al. suggested hollow sulfur sphere with $\mathrm{MnO}_{2}$ nanosheets, which effectively improved the electrochemical stability of Li-S batteries. The composites displayed capacity of $1043 \mathrm{mAh} \mathrm{g}$ ${ }^{-1}$ at the initial discharge process at $0.2 \mathrm{C}$, the capacity reached to $1196 \mathrm{mAh} \mathrm{g}^{-1}$ at the second discharge and retained at $1072 \mathrm{mAh} \mathrm{g}^{-1}$ after 200 cycles. Long cycle life are also investigated for 
1500 cycles at $0.5 \mathrm{C}$ and exhibited capacity of $644 \mathrm{mAh}^{-1}$. $\mathrm{MnO}_{2}$ decorated sulfur sphere exhibited outstanding cycling stability with high capacity retention even after 1500 cycles [13]. Recently other metal oxide composites are used as promising sulfur cathodes, not only retain dissolved polysulfides products but also buffer the volume change during the charge/discharge processes. For example Seh et al. suggested a $\mathrm{TiO}_{2}-$ sulfur yolk-shell composite that showed prolonged cyclability over 1000 cycles, minimizing polysulphide dissolution [14]. They reported an initial specific capacity of $1030 \mathrm{mAh} \mathrm{g}^{-1}$ and capacity decay per cycle was as small as $0.033 \%$ at $0.5 \mathrm{C}$. Improvement in capacity retention and coulombic efficiency refer to metal oxide shells' high electrostatic attraction toward lithium polysulphides which led to trap dissolved polysulfides. Another promising approach employed recent years is the addition of hydrophilic and polar host oxide materials such as mesoporous $\mathrm{SiO}_{2}, \mathrm{MgO}, \mathrm{Al}_{2} \mathrm{O}_{3}, \mathrm{TiO}_{2}, \mathrm{Ti}_{4} \mathrm{O}_{7}$, and $\mathrm{MnO}_{2}$ in the sulfur cathode, which effectively trapped the polysulfides [15-21].

Herein $\mathrm{MgO} / \mathrm{PDAAQ} / \mathrm{S}$ cathode is suggested as an efficient cathode for trapping polysulfides and increasing redox reactions. The CR2032-type coin cells were assembled with $\mathrm{MgO} / \mathrm{PDAAQ} / \mathrm{S}$ composite cathode, one and double side coated separator, lithium metal anode and electrolyte in an argon filled glove box. $\mathrm{MgO} / \mathrm{PDAAQ} / \mathrm{S}$ cathode and double sides coated separator showed the highest capacity of $\sim 1250$ and 1170 at $2 \mathrm{C}$ and $5 \mathrm{C}$ respectively. Coulombic efficiencies were about $96 \%$ for the cells with $\mathrm{MgO} / \mathrm{PDAAQ} / \mathrm{S}$ composite cathodes with and without coatings on the separator at $2 \mathrm{C}$. 


\section{Experimental Section}

\subsection{Materials}

Magnesium oxide (MgO, nanopowder, $\leq 50 \mathrm{~nm}$ particle size, Sigma-Aldrich), Graphene oxide (L-GO, $4 \mathrm{mg} / \mathrm{mL}$ dispersion in $\mathrm{H}_{2} \mathrm{O}$, Sigma-Aldrich), titanium dioxide $\left(\mathrm{TiO}_{2}\right.$, Rutile nanopowder, $21 \mathrm{~nm}$ particle size, $\geq 99.5 \%$ trace metals basis, Sigma-Aldrich), multi wall carbon nanotube (MWCNT > 98\% carbon basis, Sigma-Aldrich), sulfur (S, 99.5-100.5\%, SigmaAldrich), poly 1, 5-Diamino anthraquinone (PDAAQ, 85\%,148 Mw 238.24 g/mol, SigmaAldrich), potassium functionalized graphene nanoplates (K-FGF, hydrophilic, Sigma-Aldrich), cyltrimethylammonium bromide (CTAB, BioXtra $\geq 99 \%$, Sigma-Aldrich), N-methyl-2pyrrolidone (NMP, 99\%, Sigma-Aldrich), polyvinylidene fluoride (PVDF, Mw 1000-1200 kg/mol, Solef 5130, Solvay), 1,3-dioxolane(DOL,99\%,Sigma-155Aldrich),1,2- dimethoxyethane (DME,99.5\%,Sigma-Aldrich),sulfur (S,99.5-100.5\%, Sigma-Aldrich),bis(trifluoromethane) sulfonamide lithium (LiTFSI, 99.95\% trace metals basis, Sigma-Aldrich), lithium nitrate $\left(\mathrm{LiNO}_{3}\right.$, 99.99\%, trace metal basis, Sigma-Aldrich), were used without further purification. Glass microfiber filters (Whatman, Grade GF/C) were used as basis for coating.

\subsection{Cathode Preparation:}

In this study $\mathrm{MgO} / \mathrm{PDAAQ} / \mathrm{S}$ cathode is suggested as an efficient cathode for trapping polysulfides and increasing redox reactions. First 60\% Sulfur with 20\% PDAAQ and 10\% MgO nanopowders with $10 \mathrm{wt} \%$ PVDF in NMP were added and grinded together in an agate mortar and mixed. To satisfy an optimal viscosity for the electrode preparation, the addition of $3 \mathrm{ml}$ NMP is recommended. All components were stirred together until homogenous slurry was 
obtained. Prepared homogenous slurry was coated at a thickness of $60 \mu \mathrm{m}$ using doctor-blade technique on $\mathrm{Al}$ foil. (Figure 1)

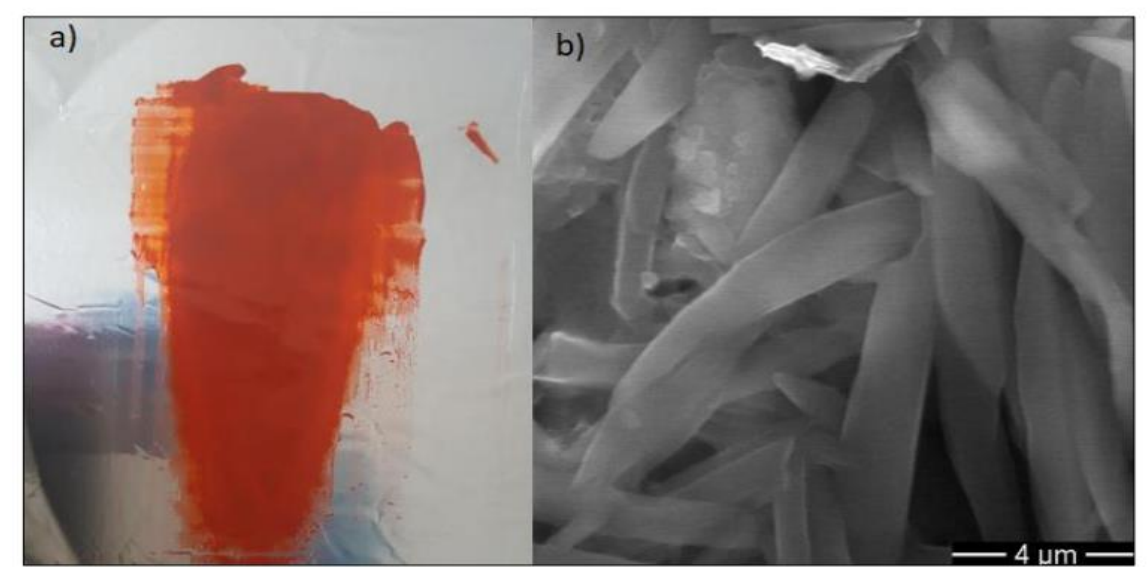

Figure. 1: a) Coated MgO-PDAAQ-S cathode on Al foil b) High resolution SEM image of $\mathrm{MgO} / \mathrm{PDAAQ} / \mathrm{S}$ cathode.

\subsection{Separators preparation}

A mixture of K-FGF and PDAAQ with a mass ratio of 4:1 was placed in an agate mortar and ground for 30 minutes to obtain the K-FGF/PDAAQ composite. Then, LGO was added to this composite with a mass ratio of 1:8 and stirred for 30 minutes. The slurry was then coated on one side of a glass fiber separator and dried in a vacuum oven at $60^{\circ} \mathrm{C}$ for 24 hours. Subsequently PVDF binder in NMP (12 wt\% PVDF binder in NMP solvent) was added to as prepared KFGF/PDAAQ composite with a mass ratio of 1:8. The K-FGF/PDAAQ/PVDF-NMP mixture was placed in N-methyl-2- pyrrolidinone solution (NMP), which was then ground for 30 minutes to form homogeneous slurry. The slurry was then coated on the other side of a glass fiber separator and dried in an air oven at $60^{\circ} \mathrm{C}$ for 24 hours. For $\mathrm{TiO}_{2}$ doped $\mathrm{K}$-FGF coating, a mixture of $\mathrm{K}$ - 
FGF and $\mathrm{TiO}_{2}$ nanoparticles with a mass ratio of 4:1 was placed in an agate mortar and ground for 30 minutes to obtain the $\mathrm{K}-\mathrm{FGF} / \mathrm{TiO}_{2}$ composite. Then, $\mathrm{L}-\mathrm{GO}$ was added to this composite with a mass ratio of 1:8 and stirred for 30 minutes. The slurry was then coated on one side of a glass fiber separator and dried in a vacuum oven at $60^{\circ} \mathrm{C}$ for 24 hours. For CTAB doped K-FGF coated separator, $\mathrm{CTAB}$ was added to K-FGF with a mass ratio of 1:4, and placed in an agate mortar and ground for 30 minutes to obtain the K-FGF/CTAB composite. Then, L-GO was added to this composite with a mass ratio of 1:8 and stirred for 30 minutes. The slurry was then coated on one side of a glass fiber separator and dried in an air oven.

For K-FGF doped PDAAQ/MWCNT/CTAB coating, mixture of K-FGF, PDAAQ and MWCNT with a mass ratio of 4:1:4 was placed in an agate mortar and ground for 30 minutes to obtain the K-FGF/PDAAQ/MWCNT composite. Then, CTAB was added to this composite with a mass ratio of 1:4. Subsequently, PVDF-NMP solution (12 wt. \% PVDF binder in NMP solvent) was added to as prepared K-FGF/PDAAQ/MWCNT/CTAB composite with a mass ratio of 1:8. The K-GF/PDAAQ/MWCNT/PVDF-NMP homogeneous slurry was formed. The slurry was then coated on the cathode-facing side of a glass fiber separator and dried in air oven at $60^{\circ} \mathrm{C}$ for 12 hours. The CR2032-type coin cells were assembled with MgO/PDAAQ/S composite cathode, one and double side coated glass fiber separator, lithium metal anode and electrolyte in an argon filled glove box.

\subsection{Electrolyte preparation}

$1 \mathrm{M}$ bis (trifluoromethane) sulfonamide lithium (LiTFSI) and $0.5 \mathrm{M}$ lithium nitrite $\left(\mathrm{LiNO}_{3}\right)$ in a solvent mixture of 1,3- dioxolane (DOL) and 1,2-dimethoxyethane (DME) (1:1) was considered as an efficient electrolyte for polysulfides trapping. Amount of electrolyte in different coin cells was fixed at $20 \mu \mathrm{L} / \mathrm{mg}$ of S. 


\section{Results and Discussion}

Li-S cell with $\mathrm{MgO} / \mathrm{PDAAQ} / \mathrm{S}$ cathode and $\mathrm{K}-\mathrm{FGF} / \mathrm{TiO}_{2} / \mathrm{L}-\mathrm{GO}$ (cathode-facing) and $\mathrm{K}$ FGF/PDAAQ/PVDF-NMP (anode -facing) side coated separator at current density of $1 \mathrm{C}$ delivers initial capacity of $1568 \mathrm{mAh} \mathrm{g}^{-1}$ and reversible capacities of 1289 and $1187 \mathrm{mAh} \mathrm{g}^{-1}$ after 100 and 200 cycles respectively. (Figure 2 )

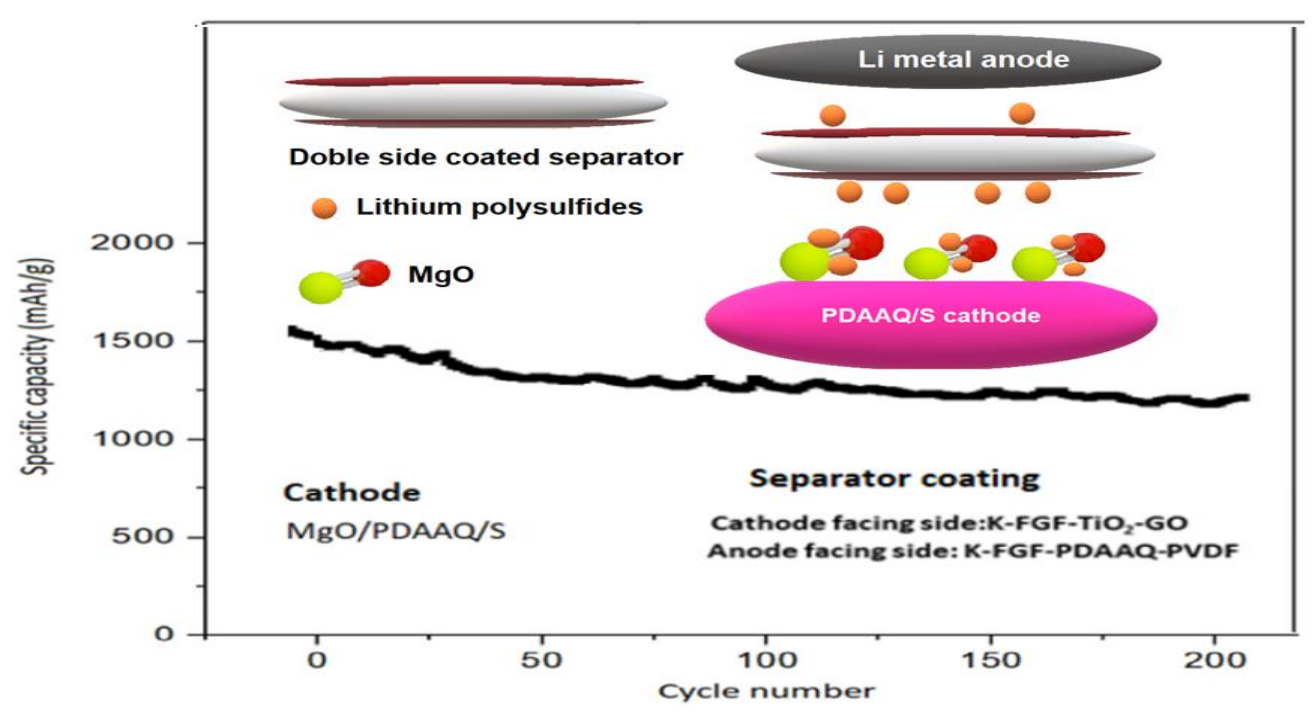

Figure. 2: Cycling performance of $\mathrm{Li}-\mathrm{S}$ cell with $\mathrm{MgO} / \mathrm{PDAAQ} / \mathrm{S}$ cathode and $\mathrm{KFGF} / \mathrm{TiO}_{2} / \mathrm{L}-$ GO (cathode-facing) and K-FGF/PDAAQ/PVDF-NMP (anode - facing) side coated separator at current density of $1 \mathrm{C}$.

Li-S cell with $\mathrm{MgO} / \mathrm{PDAAQ} / \mathrm{S}$ cathode and K-FGF/CTAB/L-GO (cathode-facing) and KFGF/PDAAQ/PVDF-NMP (anode -facing) side coated separator at current density of $1 \mathrm{C}$ delivers initial capacity of $1743 \mathrm{mAh} \mathrm{g}^{-1}$ and reversible capacities of 1019 and $991 \mathrm{mAh} \mathrm{g}^{-1}$ after 100 and 200 cycles respectively. (Figure 3) 


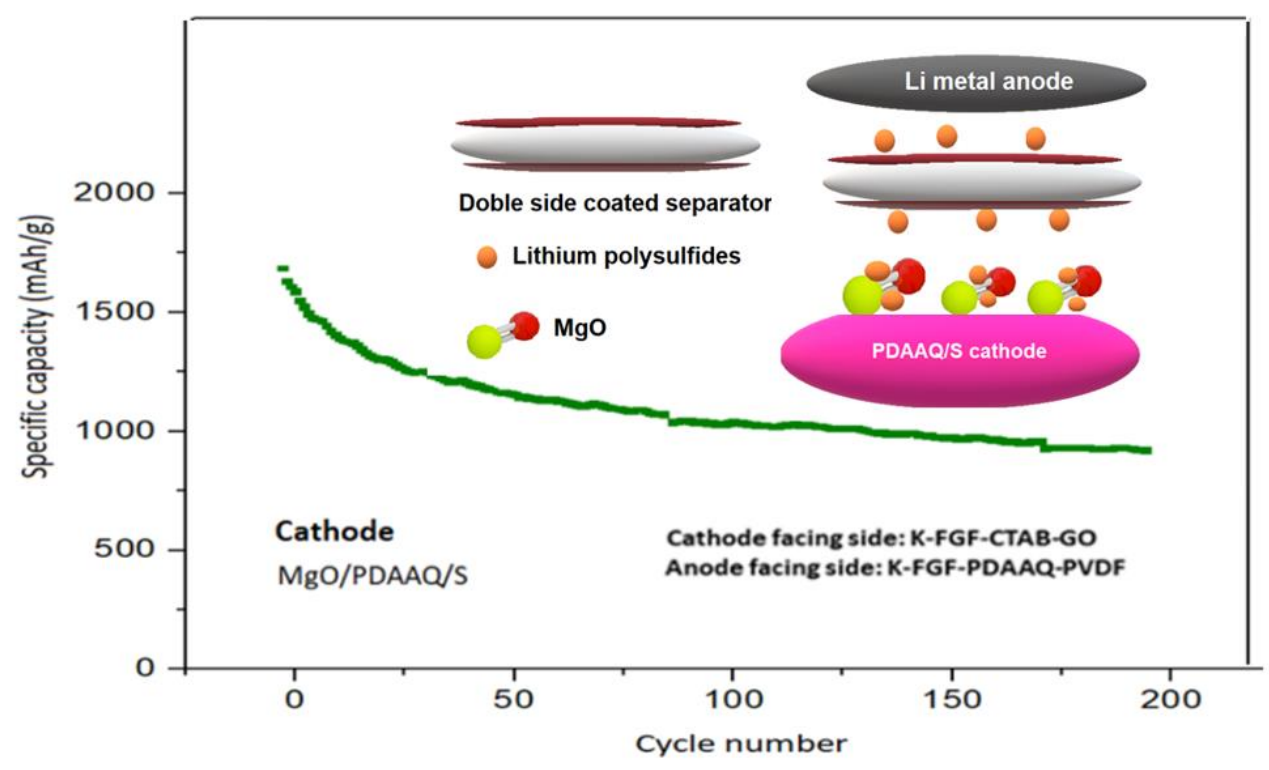

Figure. 3: Cycling performance of Li-S cell with MgO/PDAAQ/S cathode K-FGF/CTAB/L-GO (cathode-facing) and K-FGF/PDAAQ/PVDF-NMP (anode -facing) side coated separator at current density of $1 \mathrm{C}$.

Li-S cell with MgO/PDAAQ/S cathode and K-FGF/ PDAAQ/MWCNT/CTAB/PVDF-NMP (cathode -facing) side coated separator at current density of $1 \mathrm{C}$ displays initial capacity of 1257 $\mathrm{mAh} \mathrm{g}^{-1}$ and reversible capacities of 1021 and $828 \mathrm{mAh} \mathrm{g}^{-1}$ after 100 and 200 cycles respectively. (Figure 4) 


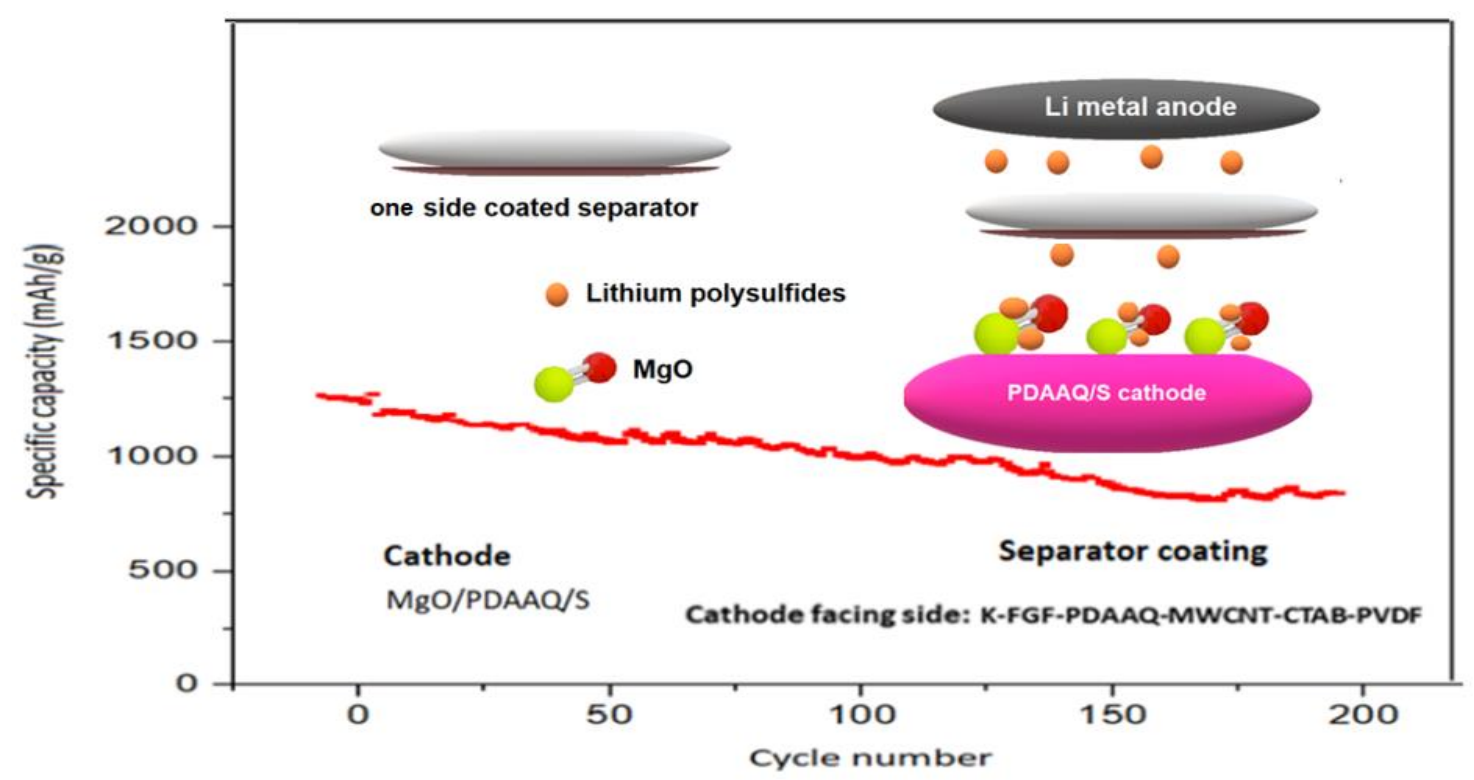

Figure. 4: Cycling performance of Li-S cell with MgO/PDAAQ/S cathode and K-FGF/ PDAAQ/MWCNT/CTAB/PVDF/NMP (cathode -facing) side coated separator at $1 \mathrm{C}$.

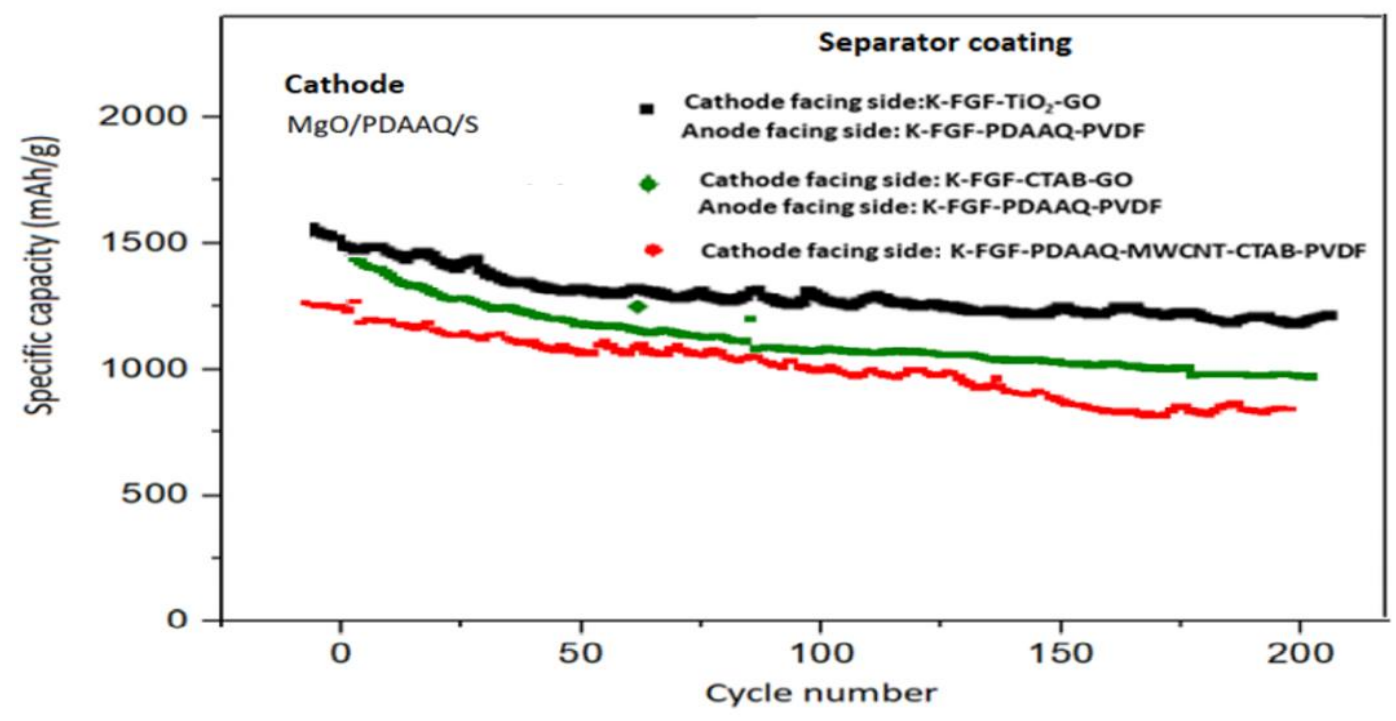

Figure. 5: Cycling performance of Li-S cell with $\mathrm{MgO} / \mathrm{PDAAQ} / \mathrm{S}$ cathode and three different coated glass fiber separators at $1 \mathrm{C}$. 
Li-S cell with $\mathrm{MgO} / \mathrm{PDAAQ} / \mathrm{S}$ cathode and $\mathrm{K}-\mathrm{FGF} / \mathrm{TiO}_{2} / \mathrm{L}-\mathrm{GO}$ (cathode-facing) and $\mathrm{K}$ FGF/PDAAQ/PVDF-NMP (anode -facing) side coated separator at current density of $1 \mathrm{C}$ delivers initial capacity of $1568 \mathrm{mAh} \mathrm{g}^{-1}$ and reversible capacities of 1289 and $1187 \mathrm{mAh} \mathrm{g}^{-1}$ after 100 and 200 cycles respectively. Li-S cell with MgO/PDAAQ/S cathode and KFGF/CTAB/L-GO (cathode-facing) and K-FGF/PDAAQ/PVDF-NMP (anode-facing) side coated separator at current density of $1 \mathrm{C}$ delivers initial capacity of $1743 \mathrm{mAh} \mathrm{g}^{-1}$ and reversible capacities of 1019 and $991 \mathrm{mAh} \mathrm{g}^{-1}$ after 100 and 200 cycles respectively. Li-S cell with MgO/PDAAQ/S cathode and K-FGF/ PDAAQ/MWCNT/CTAB-PVDF/NMP (cathode -facing) side coated separator at current density of $1 \mathrm{C}$ displays initial capacity of $1257 \mathrm{mAh} \mathrm{g}^{-1}$ and reversible capacities of 1021 and $828 \mathrm{mAh} \mathrm{g}^{-1}$ after 100 and 200 cycles respectively. (Figure 5)

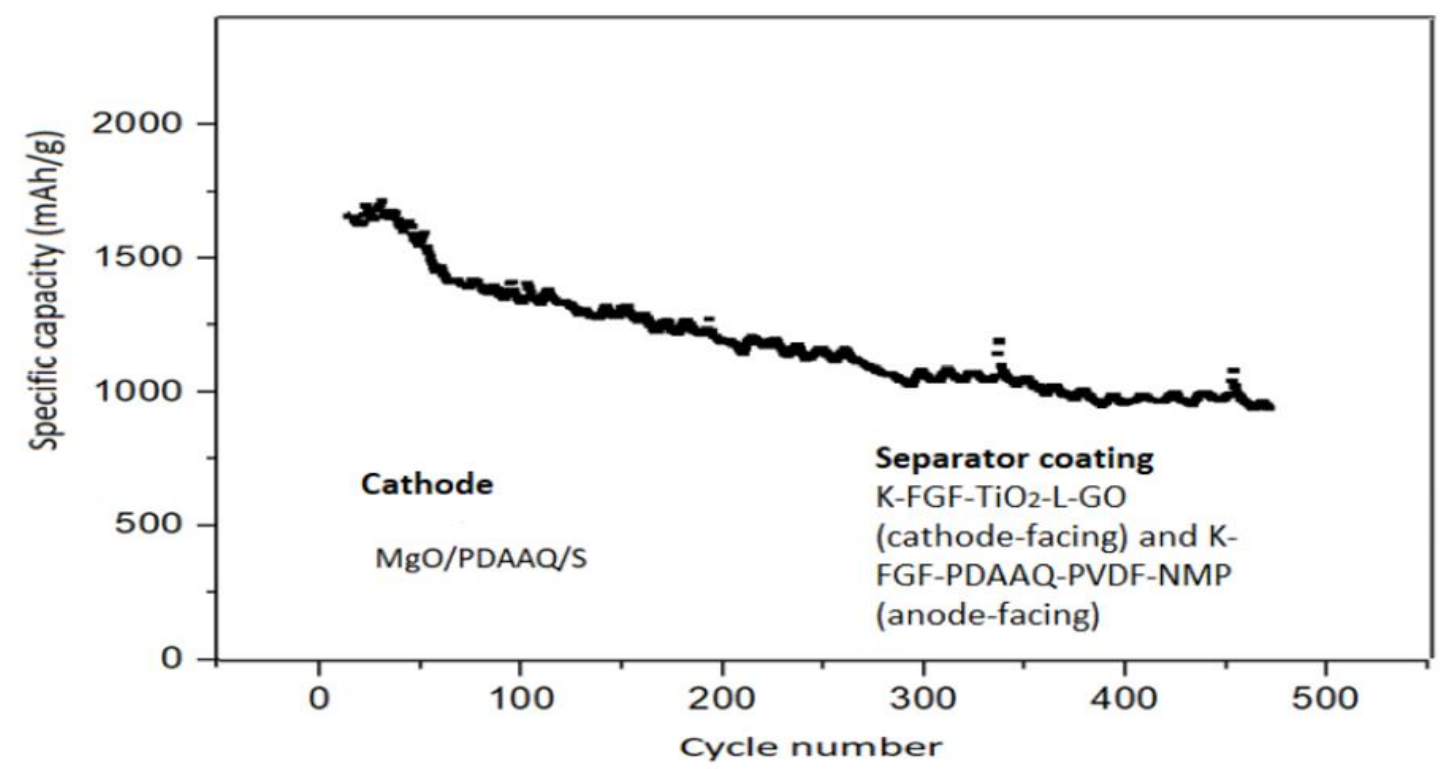

Figure. 6: Prolonged cycling stability of Li-S cell with MgO/PDAAQ/S cathode and $\mathrm{KFGF}_{\mathrm{TiO}}$ /L-GO (cathode-facing) and K-FGF/PDAAQ/PVDF-NMP (anode -facing) side coated separator at $1 \mathrm{C}$. 
Li-S cell with $\mathrm{MgO} / \mathrm{PDAAQ} / \mathrm{S}$ cathode and $\mathrm{K}-\mathrm{FGF} / \mathrm{TiO}_{2} / \mathrm{L}-\mathrm{GO}$ (cathode-facing) and KFGF/PDAAQ/PVDF-NMP (anode -facing) side coated separator at current density of $1 \mathrm{C}$ delivers initial capacity of $1568 \mathrm{mAh} \mathrm{g}^{-1}$ and reversible capacity of $998 \mathrm{mAh} \mathrm{g}^{-1}$ after 500 cycles. (Figure 6)

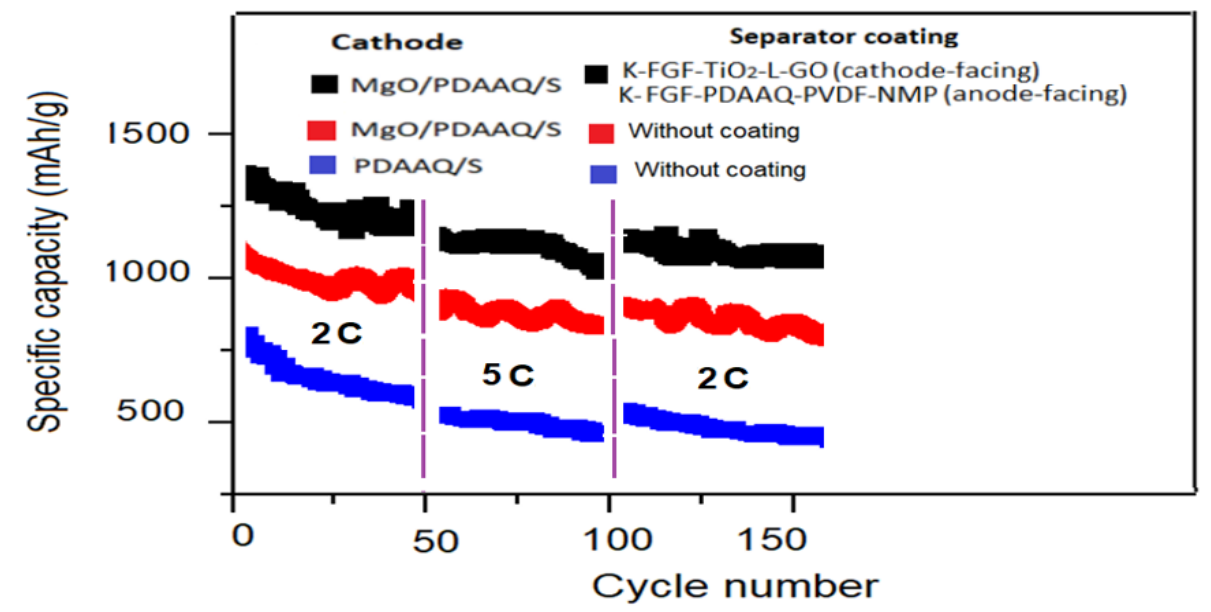

Figure. 7: Cycling performance of Li-S cell with MgO/PDAAQ/S and PDAAQ/S cathodes and coated and uncoated separators at different current densities.

To further investigate the effect of $\mathrm{MgO}$ sulfur cathode and coatings of glass fiber separator on the cell performance, the cycle performance of the Li-S cells with PDAAQ/S and $\mathrm{MgO} / \mathrm{PDAAQ} / \mathrm{S}$ cathodes without coatings on glass fiber separators and MgO/PDAAQ/S cathode with double side coated glass fiber separator was studied at a different $\mathrm{C}$ rates $(1 \mathrm{C}=$ $1685 \mathrm{mAh}$ ). The cells with PDAAQ/S and MgO/PDAAQ/S cathodes and uncoated separators showed decreased initial discharge capacities of $\sim 700$ and $1000 \mathrm{mAh} \mathrm{g}^{-1}$ at $2 \mathrm{C}$. The discharge capacities continued to decrease again at $\sim 500$ and $900 \mathrm{mAh} \mathrm{g}^{-1}$ for $5 \mathrm{C}$ respectively. 
$\mathrm{MgO} / \mathrm{PDAAQ} / \mathrm{S}$ cathode and coated separator showed the highest capacity of $\sim 1250$ and 1170 at $2 \mathrm{C}$ and $5 \mathrm{C}$ respectively. (Figure 7)

Coulombic efficiencies were about $96 \%$ for the cells with $\mathrm{MgO} / \mathrm{PDAAQ} / \mathrm{S}$ composite cathodes with and without coatings on the separator at $2 \mathrm{C}$ which exhibited better result in compare with the Coulombic efficiency of the cell with PDAAQ/S composite cathode at 2C. ( 85\%) (Figure 8)

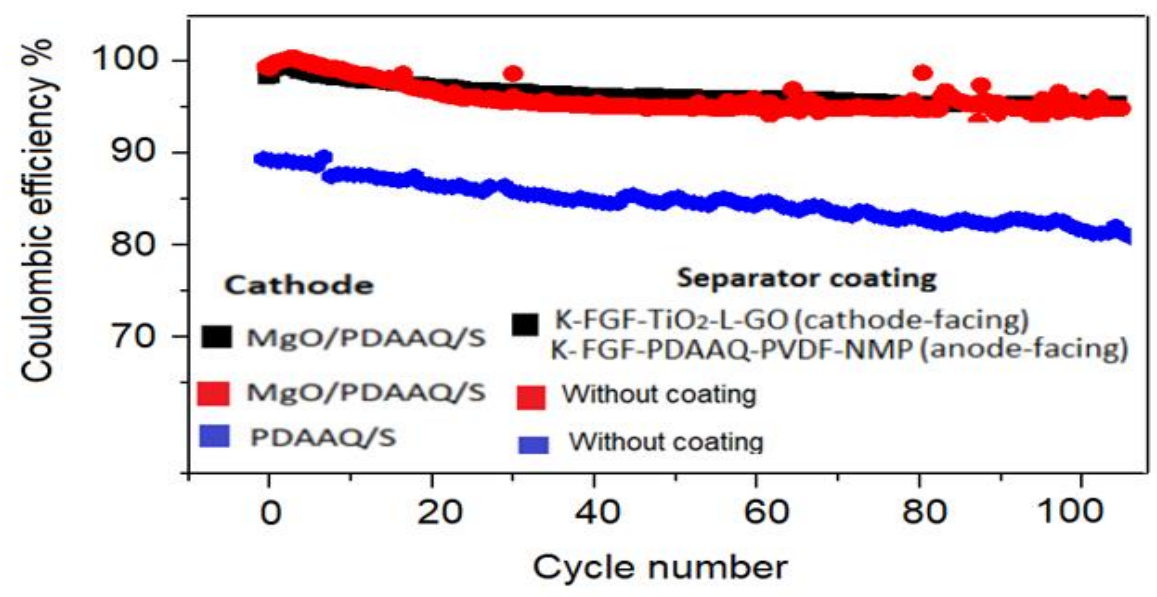

Figure. 8: Coulombic efficiencies of Li-S cells With PDAAQ/S and MgO/PDAAQ/S cathodes and coated and uncoated glass fiber separators at $2 \mathrm{C}$.

\section{Conclusion}

K-FGF coated glass fiber separator with hydrophilic head group increase polysulfides utilization in the cell and provide a conductive surface on the separator to prevent the formation of polysulfides. $\mathrm{MgO}$ nanoparticles as an additive in $\mathrm{PDAAQ} / \mathrm{S}$ cathode can be used to enhance polysulfides trapping resulted in an increase in capacity retention.

Li-S cell with $\mathrm{MgO} / \mathrm{PDAAQ} / \mathrm{S}$ cathode and $\mathrm{K}-\mathrm{FGF} / \mathrm{TiO}_{2} / \mathrm{L}-\mathrm{GO}$ (cathode-facing) and $\mathrm{K}$ FGF/PDAAQ/PVDF-NMP (anode -facing) side coated separator at current density of $1 \mathrm{C}$ 
delivers initial capacity of $1568 \mathrm{mAh} \mathrm{g}^{-1}$ and reversible capacity of $998 \mathrm{mAh} \mathrm{g}^{-1}$ after 500 cycles. The improvement in long cycling is attributed to the chemical interactions between $\mathrm{MgO}$ and lithium polysulfides as well as doped coatings on both surfaces of the separator. Addition of hydrophilic and polar host $\mathrm{MgO}$ in the PDAAQ/S cathode could entrapped the polysulfides effectively and suppressed the shuttling effect resulted in an increase in discharge capacity of 1170 and $900 \mathrm{mAh} \mathrm{g}^{-1}$ at $5 \mathrm{C}$ after 100 cycles for double side coated and uncoated glass fiber separator respectively. Further research in $\mathrm{Li}-\mathrm{S}$ batteries should be investigated not only demonstrates an effective cathode material, but also indicates the importance of separator materials on battery performance.

\section{References:}

[1] Mikhaylik, Y.V.; and Akridge, J.R. (2004). Polysulfide Shuttle Study in the Li/S Battery System, J. Electrochem. Society, 151, A1969-A1976.

[2] Diao, Y.; Xie, K.; Xiong, S.; and Hong, X. (2013). Shuttle phenomenon the irreversible oxidation mechanism of sulfur active material in Li-S battery, Journal of Power Sources, 235, 181-186.

[3] Yan, J.; Liu, X.; and Li, B. (2016). Capacity Fade Analysis of Sulfur Cathodes in Lithium-Sulfur Batteries, Advanced Science, 3, 1600101.

[4] Shim, J.; Striebel, K. A.; and Cairns, E. J. J. (2002). The lithium/sulfur rechargeable cell effects of electrode composition and solvent on cell performance, Journal of the Electrochemical Society,149, A1321-1325.

[5] Xie, Y., Meng, Z., Cai, T. and Han, W.Q. (2015). Effect of boron-doping on the graphene aerogel used as cathode for the lithium-sulfur battery, ACS applied materials \& interfaces, 7, 25202-25210. [6] Qiu, Y., Li, W., Zhao, W., Li, G., Hou, Y., Liu, M., Zhou, L., Ye, F., Li, H., Wei, Z. and Yang, S. (2014). High-rate, ultralong cycle-life lithium/sulfur batteries enabled by nitrogen-doped graphene, Nano letters, 14, 4821-4827. 
[7] Zhou, G., Paek, E., Hwang, G.S. and Manthiram, A. (2015). Long-life Li/polysulphide batteries with high sulphur loading enabled by lightweight three-dimensional nitrogen/sulphur-codoped graphene sponge, Nature communications, 6, 7760 .

[8]Gu, X., Tong, C.J., Lai, C., Qiu, J., Huang, X., Yang, W., Wen, B., Liu, L.M., Hou, Y. and Zhang, S. (2015). A porous nitrogen and phosphorous dual doped graphene blocking layer for high performance $\mathrm{Li}-$ S batteries. Journal of Materials Chemistry A, 3, 16670-16678.

[9] Pang, Q., Kundu, D., Cuisinier, M. and Nazar, L.F. (2014). Surface-enhanced redox chemistry of polysulphides on a metallic and polar host for lithium-sulphur batteries, Nature communications, 5, 4759. [10] Ji, L., Rao, M., Zheng, H., Zhang, L., Li, Y., Duan, W., Guo, J., Cairns, E.J. and Zhang, Y. (2011). Graphene oxide as a sulfur immobilizer in high performance lithium/sulfur cells, Journal of the American Chemical Society, 133, 18522-18525.

[11] Li, Y., Cai, Q., Wang, L., Li, Q., Peng, X., Gao, B., Huo, K., Chu, P.K. (2016). Mesoporous TiO 2 nanocrystals/graphene as an efficient sulfur host material for high-performance lithium-sulfur batteries, ACS Appliled Materials \& Interfaces, 8, 23784-23792.

[12] Hart, C.J., Cuisinier, M., Liang, X., Kundu, D., Garsuch, A. and Nazar, L.F. (2015). Rational design of sulphur host materials for Li-S batteries: correlating lithium polysulphide adsorptivity and selfdischarge capacity loss, Chemical Communications, 51, 2308-2311.

[13] Wang, X., Li, G., Li, J., Zhang, Y., Wook, A., Yu, A. and Chen, Z. (2016). Structural and chemical synergistic encapsulation of polysulfides enables ultralong-life lithium-sulfur batteries, Energy \& Environmental Science, 9, 2533-2538.

[14] Seh, Z.W., Li, W., Cha, J.J., Zheng, G., Yang, Y., McDowell, M.T., Hsu, P.C., Cui, Y. (2013). Sulphur- $\mathrm{TiO}_{2}$ yolk-shell nanoarchitecture with internal void space for long-cycle lithium-sulphur batteries, Nature Communication, 4, 1331.

[15] Li, Z.; Zhang, J.; and Lou, X. W. (2015). Hollow Carbon Nanofibers Filled with $\mathrm{MnO}_{2}$ Nanosheets as Efficient Sulfur Hosts for Lithium-Sulfur Batteries, Angewandte Chemie, 54, 12886-12890. 
[16] Ji, X.; Evers, S.; Black, R.; and Nazar, L. F. (2011). Stabilizing Lithium- Sulphur Cathodes Using Polysulphide Reservoirs, Nature Communications, 2, 325.

[17] Campbell, B.; Bell, J.; Bay, H. H.; Favors, Z.; Ionescu, R.; Ozkan, C. S.; and Ozkan, M. (2015). $\mathrm{SiO}_{2}$-Coated Sulfur Particles with Mildly Reduced Graphene Oxide as a Cathode Material for LithiumSulfur Batteries. Nanoscale, 7, 7051-7055.

[18] Choi, Y. J.; Jung, B. S.; Lee, D. J.; Jeong, J. H.; Kim, K. W.; Ahn, H. J.; Cho, K. K.; and Gu, H. B.

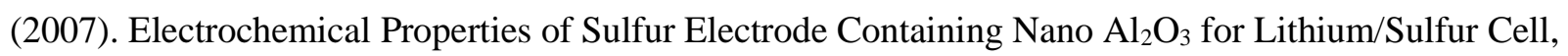
Physical Scripta, T129, 62-65.

[19] Evers, S.; Yim, T.; and Nazar, L. F. 2012. Understanding the Nature of Absorption/Adsorption in Nanoporous Polysulfide Sorbents for the Li-S Battery, Journal of Physical Chemistry C, 116, 19653-19658.

[20] Pang, Q.; Kundu, D.; Cuisinier, M.; and Nazar, L. F. (2014). Surface Enhanced Redox Chemistry of Polysulphides on a Metallic and Polar Host for Lithium-Sulphur Batteries, Nature Communications, 5, 4759.

[21] Liang, X.; Hart, C.; Pang, Q.; Garsuch, A.; Weiss, T.; and Nazar, L. F. (2015). A Highly Efficient Polysulfide Mediator for Lithium-Sulfur Batteries, Nature Communications, 6, 5682 